cases the appearance of the drum membrane and the position of the ossicles led one to believe that the contraction of adhesive bands was drawing the ossicles inwards, and exercising pressure on the intralabyrinthine fluid. The first case was operated on over twenty years ago -a nun, aged twenty-five. She suffered from constant tinnitus in the left ear, which prevented sleep, and was breaking down her health. The hearing in this ear was also very dull. The right ear was affected to a less extent. The hearing was slightly dull, but tinnitus was distressing in left ear only, in which the membrana tympani was very opaque, thickened, and indrawn, and without light-replex. Various treatments, local and general, were without avail. As a last resource the drum membrane, malleus and incus were excised. Relief of the tinnitus followed. Immediate improvement of hearing was not noted at the time, as the right ear was then relied upon, but when the left ear was tested some months later, a decided improvement was found in the hearing, both for watch and speech tests. In after years, at intervals, I have seen this case. The right ear became gradually deaf, and now, 1917, is useless. The left ear, operated on over twenty years ago for the relief of tinnitus, is quite useful. She can hear conversation in this ear in ordinary tones, and she carries on her daily life without trouble-tinnitus is not complained of. The middle ear is completely epidermised, dry and clean.

The second case was a man, hospital out-patient, with distressing tinnitus left ear. Right, normal; unable to follow his occupation of seaman. Left membrana tympani, very much indrawn. Left ear, very dull hearing. No relief from local and general treatment of usual sort. In first instance, the membrane was incised and tensor tympani divided with temporary relief. Complete relief of tinnitus, hearing for tests almost equal to good ear; patient resumed his occupation, and not seen again, so this case is useless, as an example of permanent improvement.

Case three, a very neurotic woman, hospital out-patient, a visitant of many clinics. Her complaint was distressing tinnitus aurium. Membrana tympani greatly altered. Old dry perforations, with muchthickened remains of drum membranes. Remains of drum membrane and ossicles excised in worse ear. No improvement. Here the local changes indicated a suitable case with hope of improvement.

The one clear case recorded, with well maintained and permanent improvement, shows that the experience of those who discussed Dr. Watson-Williams' paper is not universal, and that their pessimism, which has no hope for a permanent result in any case however well selected, is not justified.

\title{
DEAFNESS DUE TO THE PLACING OF CÁNDLE GREASE IN THE EXTERNAL AUDITORY MEATUS.
}

\author{
By G. E. W. Henderson, L.R.C.P. \& S.(Edin.), \\ Late Clinical Assistant, Ear, Nose, and Throat Department, Royal \\ Infirmary, Edinburgh.
}

The following case is interesting as showing what harm may be done through the agency of the lay Press in offering its readers hints on matters pertaining to health. 
Mrs. A- came to me recently complaining of complete deafness in the left ear. She stated that the deafness had come on quite suddenly. She gave no history of previous ear trouble. On examination the tuning. fork tests all pointed to a complete middle-ear deafness on the left side. On examining with the speculum I was struck by the fact that I could make out no details of the drum-head; it appeared very opaque, and there was no cone of light. I was unable to define Shrapnell's membrane. The appearance gave one the impression that there must be a catarrhal exudate in the middle ear.

A Fustachian catheter was passed, but on inflation air entered easily, and there was no moist sound.

After another careful examination through the speculum I detected what appeared to be a slight bulge outwards about the centre of the membrane.

On closely questioning the patient as to whether she had ever put anything into her ear, she informed me that she had recently been in London, and had been unable to sleep on account of the street noises outside her hotel window. Having read in a newspaper that ordinary candle grease moulded into a cone and placed in the ear made an excellent noise deadener, she had tried it. In the morning she thought the cone in the left ear had dropped out as it was not in the ear. She also stated that the weather at the time was exceedingly hot. It was now a simple matter to arrive at the diagnosis. The grease had melted and moulded itself in a thin layer completely over the membrane. To get it out presented to my mind some difficulty. Syringing with a warm alkaline solution failed completely, so I advised her to go home and have a warm solution of sodium bicarbonate in glycerine dropped into the ear several times daily for two or three days. She did this, but on her return to me there was no alteration, and after repeated syringing I came to the conclusion that as heat had been the cause of the trouble it might be used as the remedy.

I suggested that, as she was unable at the time to go from home, and as electric light was not obtainable at home, she should try lying with her ear on an ordinary rubber hot-water bottle containing very hot water. I directed her to make a "bird's nest " of cotton-wool to place round the ear in order to protect the skin from being burnt. Next day she returned for further examination. The bulge was more pronounced, and I was able to make out Shrapnell's membrane. I syringed the ear, trying to direct the stream towards the upper part of Shrapnell, and in a few minutes the wax came out. It was a small piece, and had been so closely moulded to the drum-head that the depression made by the umbo was clearly defined.

An interesting point in the case was the extraordinary resemblance the wax bore to the appearance of the drum-head in a case of catarrhal exudate in the middle ear, I confess I was completely misled at the start. 